\title{
¿Para dónde va nuestra Facultad?
}

Fabio Losada Pérez

Decano

Es común afirmar que la educación del país está en crisis. Numerosos ensayos han sido escritos para mostrar las dificultades que asedian y degradan a nuestras instituciones educativas, y numerosos los congresos que se han hecho para encontrar alternativas coherentes que han de conducimos a modelos menos conflictivos y más eficaces, pero nunca en los últimos 90 años se había legislado en materia educativa, como se pretende hacer con el proyecto de ley que hoy se encuentra en el Senado, proyecto que está siendo concertado entre el Gobierno y las comunidades comprometidas con la educación en el país.

Muchas preguntas en relación con nuestras instituciones educativas podrian guiar la reflexión, por ejemplo:

¿Implican nuestras instituciones educativas retos culturales?

¿Crean interrogantes que permitan abrir nuevos caminos hacia una democracia participativa?

¿Se reconocen la diversidad, las diferencias, los conflictos y sus posibles formas de conciliación?

¿Hay compromiso con Colombia, con el hombre colombiano, con sus valores, sus creencias?

¿Está la educación inmersa en la vida nacional?

¿Estamos contribuyendo a la formación de hombres que respondan a los paradigmas del nuevo siglo que ticnen que ver con la interfase y las pantallas, el diseño integral, los laberintos y la complejidad?
O por el contrario, ¿seguimos viviendo y reproduciendo modelos y conceptos tradicionales y arcaicos con una educación distanciada de las exigencias de la realidad?

¿Cómo responde nuestra Facultad a estos interrogantes?

Una educación que pretenda ser de calidad tiene que ser tan dinámica como la sociedad misma, para marchar al ritmo de las necesidades sociales. En este sentido la calidad de la educación se plantea como un reto para ir construyendo un cuerpo teórico que fundamente $y$ ofrezca posibilidades para pensar los procesos educativos del país y poder intervenir en su transformación y desarrollo.

La encrucijada por la que atraviesa el país no ha sido ajena a las deficiencias de un sistema educativo que forma ciudadanos para el futuro. El proceso educativo, además de transmitir unos conocimientos básicos, debe crear espiritus críticos, libres, creativos, solidarios, comprometidos con la búsqueda de la paz y la tolerancia, con la participación consciente, permanente y responsable en los procesos colectivos de manera que sea un instrumento eficaz para construir una sociedad nueva que garantice la igualdad real de oportunidades a todos los colombianos.

Por todo lo anterior es importante pensar en la calidad de la educación que nos proponemos impartir y que se busca legislar. Pero creo que la calidad de la educación no se decreta, la calidad se busca. Pero Łcómo buscar esa calidad?, ¿cómo lograrla, ¿cómo tener maestros de calidad? 
Los interrogantes son muchos y darán, a su vez, oportunidad a numerosas respuestas, pero quiero orientar la reflexión a la calidad del maestro: la calidad en la formación de los docentes puede analizarse desde 3 perspectivas:

a) La de excelencia académica de los programas que forman los maestros.

b) La de las instituciones encargadas de desarrollar dichos programas, que está relacionada con las condiciones de racionalidad y de eficiencia organizacional para el logro de la excelencia académica.

c) La del nivel de profesionalización y dignificación de la actividad docente que debe estar garantizada por el Estado, teniendo en cuenta que el maestro es un trabajador de la cultura, un intelectual, al que se le deben garantizar las condiciones para asumir su trabajo como profesional.

En el foro que sobre el proyecto de Ley General de la Educación que se realizó en el mes de septiembre del año pasado en la ciudad de Neiva tuve la oportunidad de reflexionar sobre la dignificación de la actividad docente y ahora quiero referirme a la excelencia académica de los Programas y las instituciones encargadas de desarrollar dichos programas; especialmente en la USCO.

Mirando con cuidado el desempeño académico de nuestros programas me atrevería a decir que no es excelente pero puede ameritar el de bueno. Esto se puede medir en la participación de nuestros egresados en el medio; y entre los que han tenido la

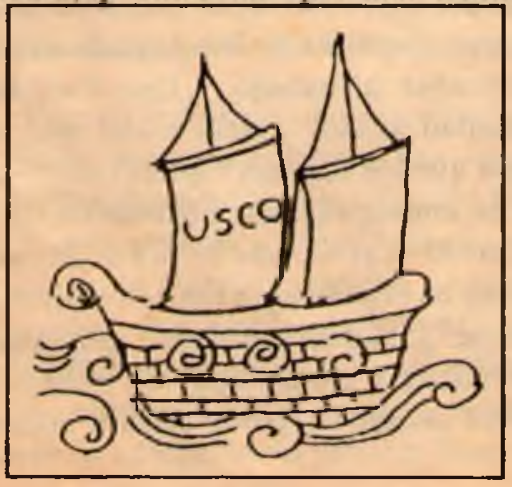

oportunidad de llegar a los postgrados satbemos que han respondido académicamente con solvencia, es el caso de unos egresados del Programa de Matemáticas y Física que se encuentran haciendo Maestría en la Universidad Nacional entre ellos destaco a Serafin Bautista, quien fue considerado como cl mejor estudiante de Matemáticas en dicha Universidad en el año 92 y por tal motivo fue acreedor al premio "MAZDA", premio que otorga esta multinacional al mejor estudiante de Matemáticas; sabemos que los demás, un grupo de 5 egresados, ha respondido de igual forma en esa universidad. Lo mismo ha ocurrido con otros egresados de la Facultad en diferentes universidades del país y con los que se han ocupado en diferentes actividades como, por ejemplo, los egresados de Educación Física quienes han aportado positivamente en los equipos profesionales de fútbol a los que han servido.

Pero no debemos contentarnos con ser buenos, debemos ser excelentes y para ello debemos modernizarnos. La Facultad lo ha intentado desde la Decanatura con el apoyo e impulso a la informática; presentando proyectos para renovar y modernizar los laboratorios y apoyando las propuestas de reestructuración académica de los Programas. Propuestas que deberán procurar armonizar con el ritmo y dinámica de nuestra sociedad actual para que puedan atender sus necesidades, y puedan intervenir en la transformación y desarrollo integral de nuestra región y del país en general. Sólo si se logra armonizar con el entorno que nos reclama podremos mantenernos dentro de la estructura de la Universidad.

Pero cuando reflexionamos en lo que hoy somos, la duda nos asalta, pues solamente se escucha cl discurso por la defensa de la Facultad, sin que se dejen ver las acciones reales. Por ejemplo, no se dejan ver los proycctos pedagógicos, las innovaciones que realizamos con nuestros estudiantes en las prácticas docentes én los jardines, cscuclas y colegios de la ciudad y la región. 
No sin el lcmor de hacerme acrecdor al calificativo de pesimista o de negativo por parle de algunos, me atrevo a recordar dos casos: 1).- Hasta hace poco visitábamos la Escucla Popular Claretiana y la Popular de Aipe para conocer sus nuevas experiencias pedagógicas, cuando el proceso debe darse a la inversa, pues deben ser los jardines, las escuclas y colegios los que acudan a la $\mathrm{U}$. para capacitarse e impulsar las propuestas alternativas que ella presenta a la comunidad educativa para el logro de la excelencia acadímica. 2) La expectativa de un profesor cooperador en un colegio de Neiva cuando le decia a un coordinador de práctica "vo a recibirle su practicante, no tanto para enseñarle, sino para aprender las cosas nuevas que se están viendo en la $U$. porque vo hace veinticinco años me gradue". Puro al final del semestre, cuando el estudiante terminó la práctica, su frustración se reveló en esta frase: "el estudiante no trajo nada nuevo, se están enseñando las mismas cosas con los mismos métodos de hace 25 años".

Miremos ahora otro aspecto de nuestra Facultad, la proyección con planes de extensión: aquí contamos con el proyecto bandera, el de Alfabetización y postalfahetización. Sus gestores han conseguido recursos, han participado en eventos nacionales en la modalidad de educación no fomal, están realizando invetigaciones interinstitucionales, pero se mantiene fundamentalmente con una actividad de práctica docente de un programa. Esto esta bien, pero no es la situación ideal.

Los egresados no tienen posibilidades de actualización, no existen los planes de educación continuada, no se concretan las propuestas de capacitación para los maestros de educación básica, lo cual, desde mi modo de ver, es apenas una consecuencia si se tiene en cuenta que en la mayoría de las carreras los profesores de tiempo completo no han querido comprometerse con la práctica profesional docente, con la formación real del maestro y las teorias que les llevamos, si no que están lejos de las necesidades reales del maestro en la educacion bisica, apenas se aproximan superficialmente.

A nivel de la investigación la situación ha ido mejorando poco a poco; pero no es suficiente si se mira, por un lado, el potencial humano con que cuenta muestra unidad académica y, por otra, la necesidad urgente de trascender, de hablar con voz propia y de confrontarnos, y de competir académ icamente, de incidir en la solución de los problemas que aquejan la educación regional, de implementar postgrados propios.

Despućs de esta reflexión surge otra inquictud. ¿Es testa la Facultad ideal?, ¿cuíl es la facultad que queremos?, ¿cómo esperamos continuar al frente de la formación de macstros? y ¿qué tal si decidiéramos no formar educadores? ¿cómo nos va con los matemáticos, con los literatos, con los lingüistas, con los entrenadores o deportistas, con las jardineras o con los recreacionistas?, ¿Existen?, ¿son buenos?

Por donde quiera que se mire nuestra unidad académica se muestra en crisis y a pesar de que hizo una autoevaluación que mostró las debilidades y fortalczas, no hemos hecho mucho para corregir y avanzar lo que se debe corregir para avanzar.

Con el ánimo de encontrar alternativas que nos conduzcan a superar este dificil momento, la Decanatura se dió a la tarea de impulsar la formación de comités de apoyo como el comité de desarrollo de la Facultad el de investigación, de extensión y práctica docente, unos han trabajado mejor que otros y se han constituido en soportes reales, mientras que otros no han logrado arrancar o enrumbar su trabajo. ¿Qué hace falta? ¿Voluntad acaso? ¿Ineentivos mayores? Pienso que los dos son ingredientes vitales que de conseguirlos contribuirian de manera positiva al repunte de la Facultad en la región y en el pais, pues existen en el cucrpo docente gtandes calidades humanas $y$ acadínicas y capacidad de trabajo con quienes estamos seguros de salir adelante. 